Provided for non-commercial research and education use. Not for reproduction, distribution or commercial use.

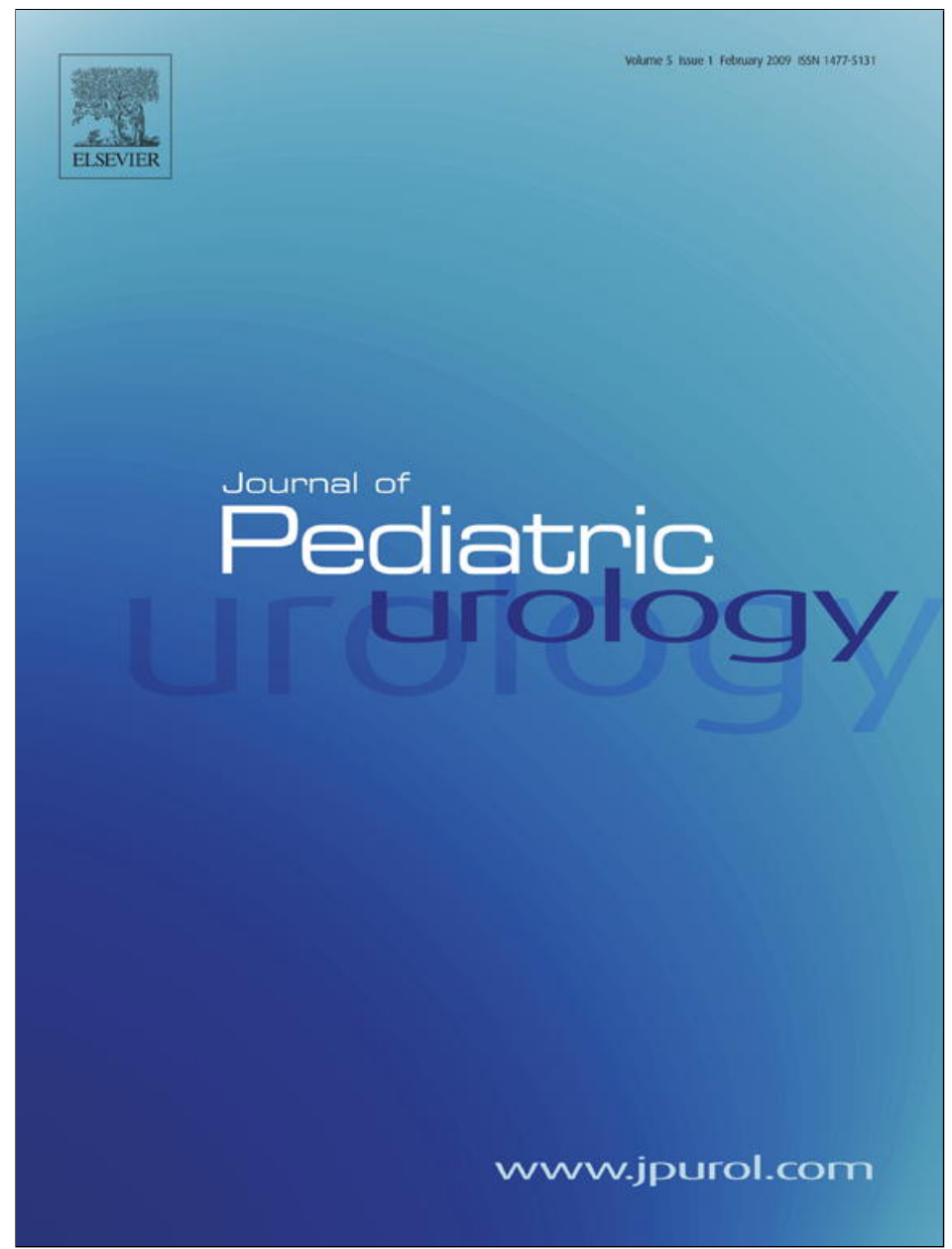

This article appeared in a journal published by Elsevier. The attached copy is furnished to the author for internal non-commercial research and education use, including for instruction at the authors institution and sharing with colleagues.

Other uses, including reproduction and distribution, or selling or licensing copies, or posting to personal, institutional or third party websites are prohibited.

In most cases authors are permitted to post their version of the article (e.g. in Word or Tex form) to their personal website or institutional repository. Authors requiring further information regarding Elsevier's archiving and manuscript policies are encouraged to visit:

http://www.elsevier.com/copyright 


\title{
Congenital hydronephrosis: Prenatal diagnosis and epidemiology in Europe
}

\author{
Ester Garne $^{\mathrm{a}, *}$, Maria Loane ${ }^{\mathrm{b}}$, Diana Wellesley ${ }^{\mathrm{c}}$, Ingeborg Barisic ${ }^{\mathrm{d}}$, \\ EUROCAT Working Group ${ }^{e}$
}

\author{
a Paediatric Department, Kolding Hospital, 6000 Kolding, Denmark \\ ${ }^{\mathrm{b}}$ University of Ulster, Belfast, UK \\ c Princess Anne Hospital, Southampton, UK \\ ${ }^{d}$ Children's University Hospital, Zagreb, Croatia
}

Received 13 May 2008; accepted 28 August 2008

Available online 5 November 2008

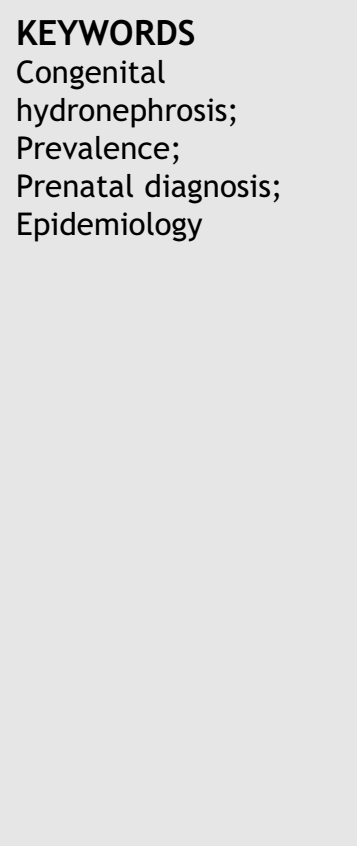

\begin{abstract}
Objective: To describe prevalence, prenatal diagnosis and epidemiology of congenital hydronephrosis $(\mathrm{CH})$ in Europe.

Material and method: Data from a large European database for surveillance of congenital malformations (EUROCAT). The 20 participating registries are all based on multiple sources of information and include information about livebirths, fetal deaths with gestational age $\geq 20$ weeks and terminations of pregnancy after prenatal diagnosis of malformations. Included were all cases with $\mathrm{CH}$ and born 1995-2004.

Results: There were 3648 cases with $\mathrm{CH}$ giving an overall prevalence of 11.5 cases per 10,000 births. The large majority of cases were livebirths (3506, $96 \%$ of total) and only 17 cases were fetal deaths and 120 were terminations of pregnancy. Almost all livebirths were alive 1 week after birth. Boys accounted for $72 \%$ of all cases. A high proportion of the cases $(86 \%)$ had an isolated renal malformation. There were large regional differences in prevalence of $\mathrm{CH}$ ranging from 2 to 29 per 10,000 births. There was little regional variation in the prevalence of postnatally diagnosed cases while there were large regional differences in prevalence of prenatally diagnosed cases.

Conclusion: Cases with $\mathrm{CH}$ are mainly livebirths, boys and survive the first week after birth. The large difference in prevalence seems to be related to the availability of prenatal screening in the region. The impact of over-diagnosis and potential over-treatment in regions with high prevalence or under-diagnosis with implications for renal function later in life in regions with low prevalence needs further investigation.
\end{abstract}

(c) 2008 Journal of Pediatric Urology Company. Published by Elsevier Ltd. All rights reserved.

\footnotetext{
* Corresponding author. Tel.: +45 7626 2219; fax: +45 76363474

E-mail address: egarne@health.sdu.dk (E. Garne).

e See appendix for EUROCAT Working Group.
} 


\section{Introduction}

The natural history of congenital hydronephrosis $(\mathrm{CH})$ has changed dramatically over the last decades. Up to the 1980 s, $\mathrm{CH}$ was mainly diagnosed in infants admitted to hospital with urosepsis or UTIs. The main diagnostic test for $\mathrm{CH}$ was intravenous urography. Later ultrasound became the first diagnostic test for investigation of renal malformations in infants. During the last 25 years an increasing number of fetuses have been diagnosed prenatally with $\mathrm{CH}$ using ultrasound investigation, either on indication or as a screening method [1].

Many European countries have now developed national or regional programmes for both prenatal and postnatal follow up and treatment for fetuses and infants with $\mathrm{CH}$. In earlier time periods most infants diagnosed with $\mathrm{CH}$ were referred for surgery in infancy. Today the majority of infants are followed up with ultrasound and/or renal functioning tests every 3 months and surgery is only recommended for a small proportion of infants and children. The main indication for surgery is decreasing function of the affected kidney [2].

A prenatal diagnosis of $\mathrm{CH}$ may increase anxiety for the expectant parents and they may ask questions that need to be answered: Is the risk of fetal or neonatal death increased? How much will the diagnosed malformation impact on the quality of life in infancy and childhood? A prenatal diagnosis of $\mathrm{CH}$ also raises the questions of whether any interventions during pregnancy will be needed and allows postnatal investigations and treatment to be planned.

The aim of this study is to present data on prevalence, prenatal diagnosis and epidemiology of $\mathrm{CH}$ in Europe using a large European database of congenital malformations (EUROCAT).

\section{Methods}

The study is based on routinely collected data from 20 European registries of congenital malformations (EUROCAT).

The EUROCAT registries are population based, and the geographically defined populations and methods of case ascertainment of EUROCAT have been described elsewhere [3]. For further details on population coverage and registration methods see www.eurocat.ulster.ac.uk/memb erreg/. The registries are all based on multiple sources of information including hospital records, birth and death certificates, and post-mortem examinations, and include information about livebirths, fetal deaths with gestational age (GA) $\geq 20$ weeks and terminations of pregnancy (TOP) after prenatal diagnosis of malformations. All structural malformations, syndromes and chromosomal anomalies are included in the database except minor and poorly specified malformations found on a list of exclusion http: // www.eurocat.ulster.ac.uk/pdf/EUROCAT-Guide-1.3.pdf.

Only cases with the diagnosis confirmed postnatally are included in the database.

All cases with an ICD9 or ICD10 code with CH (75320 and Q620) and born in the period 1995-2004 were included in this study. Cases with an additional chromosomal anomaly were excluded (173 cases). Further cases coded with both $\mathrm{CH}$ and PUV or prune belly syndrome were excluded.

The EUROCAT definition of $\mathrm{CH}$ was "obstruction of the urinary flow from kidney to bladder" and from 2003 it was added "only if renal pelvis is $10 \mathrm{~mm}$ or more after birth". According to the definition $\mathrm{CH}$ caused by VUR is not included in the EUROCAT database and is mentioned on the exclusion list.

The data included in the analysis are: birth outcome, year of birth, sex, birth weight, gestational age, time of diagnosis (prenatally or postnatally), death within first week after birth and associated malformations.

The EUROCAT flowchart for multiple malformations was used to find the potential multiple malformation cases http: / / www.eurocat.ulster.ac.uk/pdf/EUROCAT-Guide-1.3.pdf.

These cases were manually reviewed by two geneticists (DW and IB) and classified as isolated renal malformation, multiple malformations (two or more major malformations in different organ systems), syndrome or association.

A questionnaire was send to all local registries regarding the postnatal follow up and treatment of infants with $\mathrm{CH}$.

Information on prenatal screening programmes in Europe based on the situation in the year 2004 was extracted from an earlier EUROCAT publication [4]. At that time one or more prenatal ultrasound investigations was offered to all pregnant women in all countries except Ireland, Malta and Netherlands. All countries offering ultrasound screening had one scan performed in the second trimester of pregnancy.

Total number of births covered by the 20 registries in the years included in the study was 3,160,728.

\section{Results}

During the 10-year study period there were 3648 cases with $\mathrm{CH}$ reported to EUROCAT from the 20 local registries. This gives an overall prevalence of $\mathrm{CH}$ of 11.5 per 10,000 births with a large regional difference within Europe in prevalence of $\mathrm{CH}$ (Table 1 and Fig. 1).

The large majority of the cases were livebirths, 3506 (96\%), and there were only 17 fetal deaths with GA $\geq 20$ weeks and 120 TOP after prenatal diagnosis (birth outcome was unknown for 5 cases). Median GA for fetal deaths was 31 weeks (range 23-40 weeks), and median GA for TOP was 21 weeks with 90 before 24 weeks and 22 at 24 weeks or later (GA at termination was unknown for 8 cases).

Among livebirths there were 2523 boys (72\%) and 977 girls (28\%). In six livebirth cases the gender of the case was not recorded in the registry.

Time of diagnosis was prenatal in 2664 cases $173 \%$ of total cases). There were large regional differences in the proportion of prenatally diagnosed cases, ranging from less than $30 \%$ in Campania and SE Ireland to more than $80 \%$ in Basque Country (81\%), Vaud (82\%), Wales (82\%), Strasbourg (84\%), Paris (88\%) and Barcelona (95\%) (Table 1 and Fig. 1). Fig. 1 shows the relationship between overall prevalence of $\mathrm{CH}$ and the prevalence of $\mathrm{CH}$ diagnosed prenatally.

For postnatally diagnosed cases 675 of 902 cases (75\%) were diagnosed within the first week and only 17 cases were reported after 1 year of age. However, only four registries included cases diagnosed after the first year of life. 
Table 1 Time period, total birth, prevalence and age at diagnosis of $\mathrm{CH}$ by registry

\begin{tabular}{|c|c|c|c|c|c|c|c|c|c|}
\hline Registry & Country & $\begin{array}{l}\text { Years } \\
\text { included }\end{array}$ & $\begin{array}{l}\text { Total } \\
\text { births }\end{array}$ & $\begin{array}{l}\text { Total } \\
\text { cases }\end{array}$ & $\begin{array}{l}\text { Total } \\
\text { prevalence }^{a}\end{array}$ & $\begin{array}{l}\text { Cases with } \\
\text { prenatal } \\
\text { diagnosis }\end{array}$ & $\begin{array}{l}\text { Prevalence } \\
\text { prenatal } \\
\text { diagnosis }^{\mathrm{a}}\end{array}$ & $\begin{array}{l}\text { \% Prenatal } \\
\text { diagnosis }\end{array}$ & $\begin{array}{l}\text { Age at } \\
\text { postnatal } \\
\text { diagnosis }\end{array}$ \\
\hline Wielkopolska & Poland & 1999-2004 & 206,481 & 44 & 2.1 & 22 & 1.1 & 50 & $<1$ year \\
\hline N Netherlands & Netherlands & 1995-2004 & 198,521 & 71 & 3.6 & 45 & 2.3 & 63 & $<1$ year \\
\hline SE Ireland & Ireland & 1997-2003 & 41,625 & 17 & 3.6 & 4 & 1.0 & 24 & $<1$ year \\
\hline Cork and Kerry & Ireland & 1996-2003 & 63,007 & 24 & 3.8 & 13 & 2.1 & 54 & $<1$ year \\
\hline Campania & Italy & $1996-2004$ & 479,458 & 245 & 5.1 & 52 & 1.1 & 21 & $<1$ month \\
\hline Zagreb & Croatia & 1995-2004 & 59,253 & 33 & 5.6 & 22 & 3.7 & 67 & $<1$ year \\
\hline Malta & Malta & 1995-2004 & 43,128 & 24 & 5.6 & 17 & 3.9 & 71 & $<1$ week \\
\hline S Portugal & Portugal & $\begin{array}{l}1995-1998 \\
2000-2004\end{array}$ & 155,882 & 98 & 6.3 & 69 & 4.4 & 70 & $<1$ month \\
\hline Basque & Spain & $1995-2004$ & 173,245 & 116 & 6.7 & 94 & 5.4 & 81 & $<1$ year \\
\hline Tuscany & Italy & 1995-2004 & 261,867 & 205 & 7.8 & 125 & 4.8 & 61 & $<1$ year \\
\hline Odense & Denmark & 1995-2004 & 55,677 & 44 & 7.9 & 29 & 5.2 & 66 & $>1$ year \\
\hline Vaud & Switzerland & 1995-2004 & 73,544 & 77 & 10.5 & 63 & 8.6 & 82 & $>1$ year \\
\hline Barcelona & Spain & $1995-2003$ & 113,133 & 131 & 11.6 & 125 & 11.0 & 95 & $<1$ week \\
\hline IMER & Italy & 1995-2004 & 269,875 & 325 & 12.0 & 210 & 7.8 & 65 & $<1$ year \\
\hline Strasbourg & France & 1995-2001 & 94,802 & 122 & 12.9 & 103 & 10.9 & 84 & $>1$ year \\
\hline Mainz & Germany & 1995-2004 & 33,419 & 63 & 18.9 & 29 & 8.7 & 46 & $<1$ week \\
\hline Paris & France & 1995-2004 & 382,584 & 814 & 21.3 & 777 & 20.3 & 95 & $<1$ week \\
\hline Styria & Austria & $1995-2004$ & 110,529 & 238 & 21.5 & 135 & 12.2 & 57 & $<1$ year \\
\hline Hainaut & Belgium & 1995-2004 & 122,389 & 312 & 25.5 & 198 & 16.2 & 63 & $<1$ year \\
\hline Wales & UK & 1998-2004 & 222,309 & 645 & 29.0 & 532 & 23.9 & 82 & $>1$ year \\
\hline Total & & & $3,160,728$ & 3648 & 11.5 & 2664 & 8.4 & 73 & \\
\hline
\end{tabular}

The cases were classified into three groups: 3135 (86\%) cases had an isolated renal malformation, $416(11 \%)$ were multiple malformed, and $97(3 \%)$ were diagnosed with a recognized syndrome or association. Among the multiple malformed cases there were 47 cases with hypospadia ( $11 \%$ of all multiple malformed) and 57 cases with a ventricular septal defect (14\% of all multiple malformed cases).

Among livebirths 3078/3506 (88\%) had an isolated renal malformation compared to $46 / 120(38 \%)$ of TOP $(P<0.001)$ (Table 2).
Comparing registries there was a clear relationship between the total prevalence of $\mathrm{CH}$ and the prevalence of $\mathrm{CH}$ as an isolated renal malformation (Fig. 2).

GA at prenatal diagnosis was available for 1733 liveborn infants with an isolated renal malformation. The most frequent GAs at diagnosis were 19-22 weeks and 32-34 weeks (Fig. 3). These are the usual ages at which ultrasound screening is offered in the second and third trimesters [4].

Fifteen registries had information on survival until 1 week after birth. Only 17 of 2051 cases (0.8\%) were

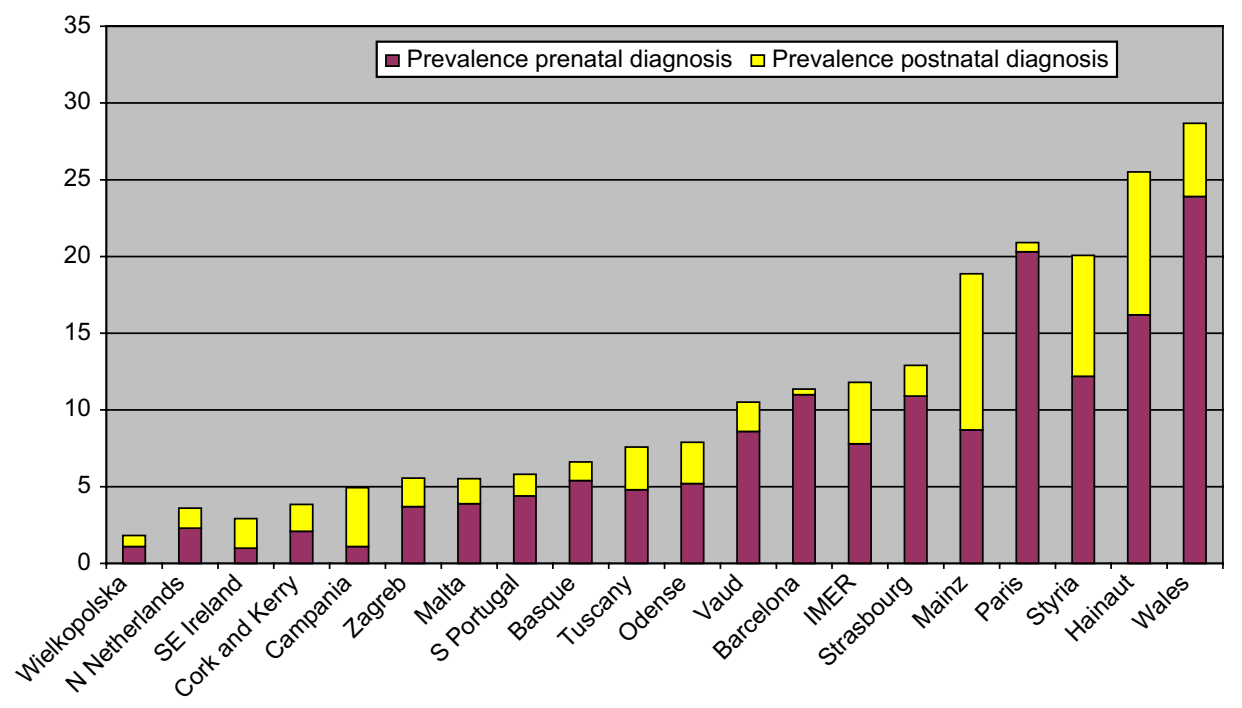

Figure 1 Total prevalence and prevalence of prenatally diagnosed cases with $\mathrm{CH}$ by registry, sorted by total prevalence. 
Table 2 Relation between birth outcome and associated malformations for cases with $\mathrm{CH}$

\begin{tabular}{lllc}
\hline & TOP & Fetal death & Livebirth \\
\hline Isolated renal & $46(38 \%)$ & $8(47 \%)$ & $3078(88 \%)$ \\
Multiple malformations & $59(49 \%)$ & $7(41 \%)$ & $349(10 \%)$ \\
Syndrome or association & $15(13 \%)$ & $2(12 \%)$ & $79(2 \%)$ \\
Total & 120 & 17 & 3506 \\
\hline
\end{tabular}

reported with a date of death within the first week and 1979 cases were alive at 1 week of age. Survival was unknown for 55 cases (2.7\%) from these 15 registries.

\section{Discussion}

This study found an overall prevalence of $\mathrm{CH}$ in European regions of 11.5 per 10,000 births with a large regional difference. Very few studies have been published on the prevalence of $\mathrm{CH}$ for comparison with our study. Studies on prenatally detected $\mathrm{CH}$ show a rate as high as $1 \%$, but these studies also included less severe cases that resolved spontaneously after birth [5,6]. We are aware of three studies published from 1989 to 1993. A British study [7] found 13 cases in 6292 pregnant women reaching 28 weeks of gestation, the age at which the ultrasound was performed. One case was diagnosed postnatally and 12 cases prenatally. The prevalence of $\mathrm{CH}$ in this study was 20.7 per 10,000 births. In Finland they found 14 cases in 4586 fetuses (one diagnosed postnatally) giving a prevalence of 30.5 per 10,000 births [8].

A large population-based British study based on notifications to a registry found 113 cases in 242,628 births giving a prevalence of 4.7 per 10,000 births [9]. In this study 97 cases were diagnosed prenatally ( $86 \%$ of total cases).

There are several limitations to our study. First of all we did not have a clear definition of the severity of $\mathrm{CH}$ before
2003. At that time it was decided to include only those cases with a renal pelvis of at least $10 \mathrm{~mm}$ after birth. There may be less severe cases included before 2003 or the size of the renal pelvis may be unknown to the registry. Total prevalence for $\mathrm{CH}$ was 9.1 per 10,000 births for the years 2003-2004 compared to 11.5 per 10,000 births for the whole study period. This decrease is not wholly explained by a change in definition as some registries include late diagnosed cases, which means that cases born in 2004 may not have been reported to the central database at the time of data extraction for the study.

Although we do not include $\mathrm{CH}$ based on VUR, there may be cases notified to the local registries where the etiology of the $\mathrm{CH}$ was not yet known. We know that this has occurred in Wales, Styria and Mainz and may explain part of their high prevalence.

Some registries only include cases diagnosed within the first week of life and have difficulties in the follow up of cases after the first discharge from hospital. Table 1 shows the maximum age at diagnosis by registry for cases included in the study. Four registries only include cases diagnosed up to 1 week after birth and three of these have a low postnatal prevalence of $\mathrm{CH}$ (Barcelona, Malta and Paris) (Fig. 1).

Furthermore, we are not able to discriminate between unilateral and bilateral $\mathrm{CH}$. The data are extracted based on the ICD code, and there is only one code for $\mathrm{CH}$ in both ICD9 and ICD10. This means that we do not know if all TOP were cases with bilateral $\mathrm{CH}$.

The strength of our study is the large dataset collected over many years. The database is without bias in collecting data specific for $\mathrm{CH}$, and we have good data on both prenatal diagnosis and postnatal confirmation of the diagnosis.

Despite the limitations, we can conclude that there are very large regional differences in the prevalence of $\mathrm{CH}$ in Europe. The large difference in prevalence in this study seems to be explained by differences in prenatal diagnosis. The three countries with no prenatal ultrasound screening

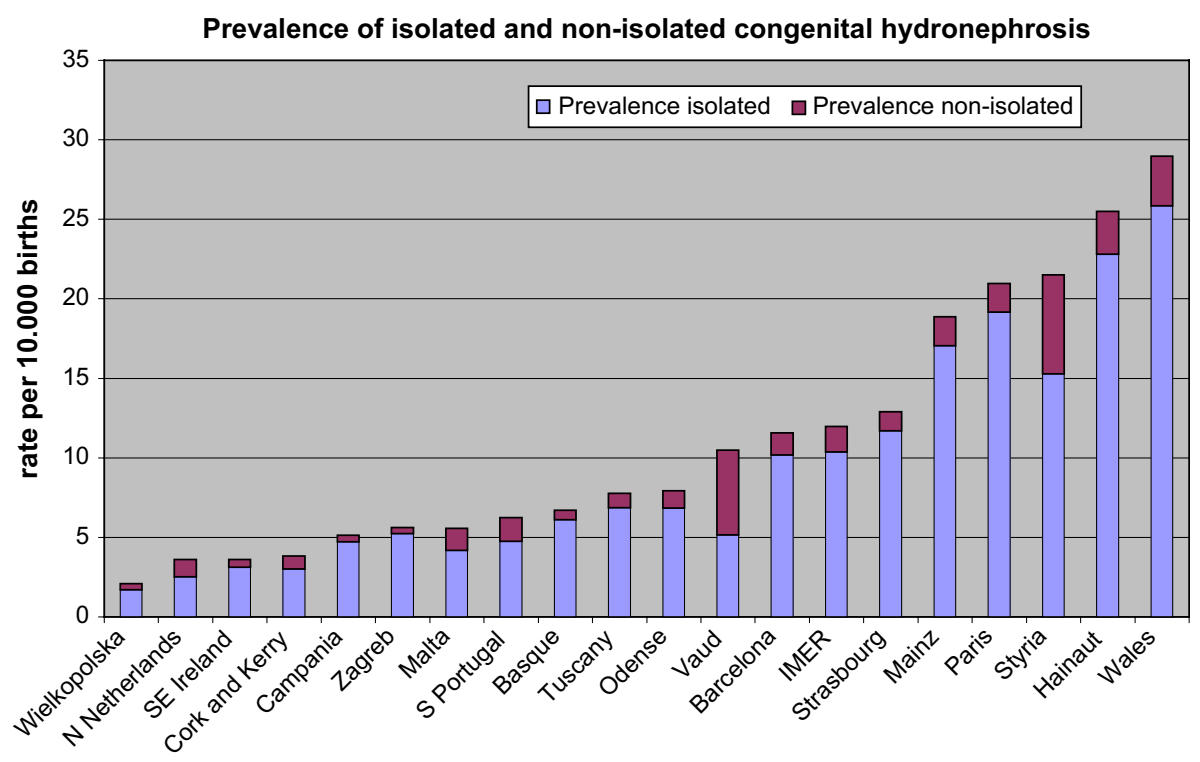

Figure 2 Prevalence of isolated and non-isolated cases with $\mathrm{CH}$, by registry. 


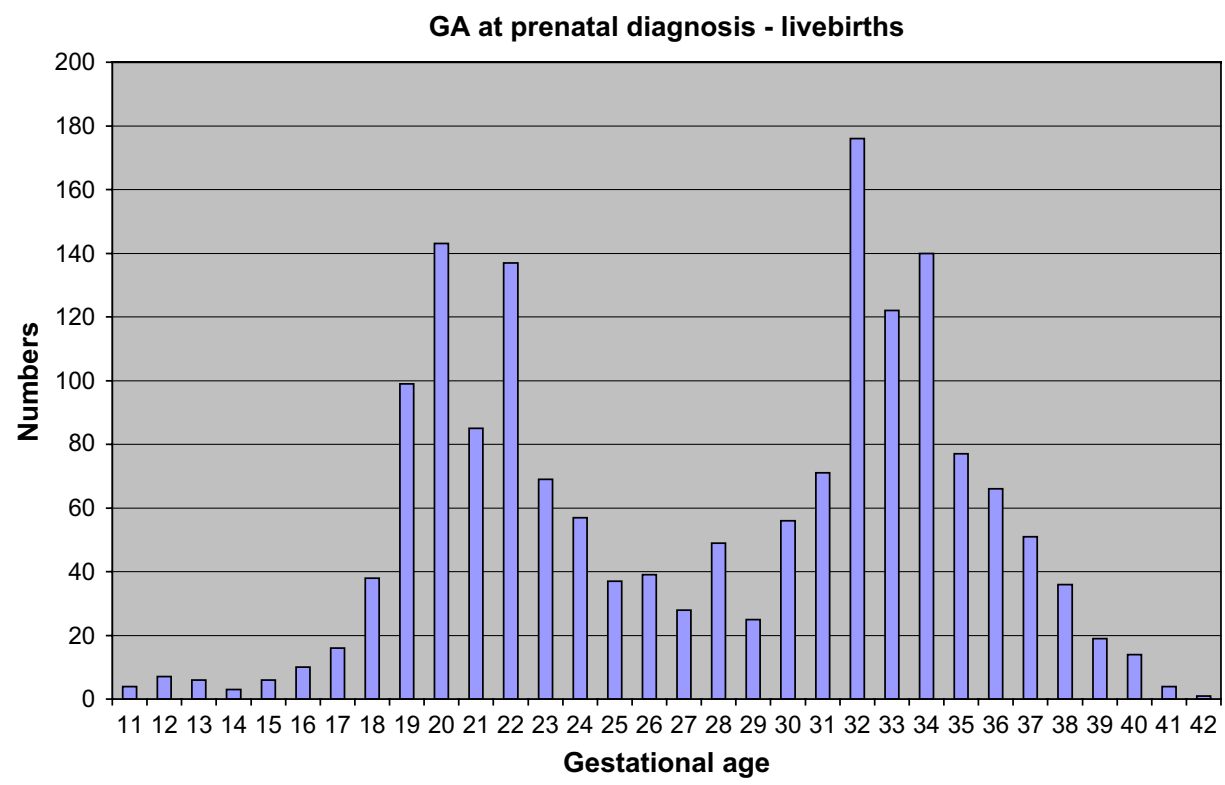

Figure $3 \mathrm{GA}$ at diagnosis for liveborn infants with isolated $\mathrm{CH}$.

offered during the whole study period all had a low prevalence at 3.6-5.6 per 10,000 births (Ireland, Malta and Netherlands). Many countries with a second trimester screening offered also offered a third trimester scan, although mainly for biometric purposes. Among these countries (Austria, Belgium, France, Germany, Italy, Portugal and Spain) [4] most had a high prevalence of $\mathrm{CH}$. The number of postnatally diagnosed cases and the number of cases with associated anomalies seem to be more uniform than the prevalence of prenatally diagnosed and isolated cases with $\mathrm{CH}$ (Figs. 1 and 2).

However, the definition of $\mathrm{CH}$ needs to be standardized. Comparison of regional prevalence is difficult due to between-country variations in the use of prenatal ultrasound investigations, different interpretations of the definition of $\mathrm{CH}$ and the availability of follow-up data for each case. These factors contribute to the overall regional prevalence of $\mathrm{CH}$.

The typical case with $\mathrm{CH}$ is a liveborn boy who is alive 1 week after birth. We found a highly significant difference in the rate of associated anomalies between livebirths and TOP. TOP were performed in only 46 out of 3135 cases with isolated renal malformation. In the European regions included in this study the diagnosis of fetal hydronephrosis is only on rare occasions followed by TOP. In some countries such as Poland TOP are only allowed for severe, usually lethal anomalies and not allowed for $\mathrm{CH}$.

Many areas have a regional follow-up programme for infants diagnosed with $\mathrm{CH}$ and we are aware of follow-up programmes in Wales, Spain and Denmark [10]. These includes regular ultrasound investigations, renal function tests and in some places also prophylactic antibiotics. From the questionnaire to the local registries we also know that prophylactic antibiotics are given in Wales, Basque Country and Croatia.

Surgery is performed if renal function is/becomes impaired, although there may also be other indications such as size, pain or recurrent infections. The actual clinical controversy is that there is currently no way of differentiating between "harmful" and "harmless" obstruction [1]. The management approach must balance the costs and risks of universal surgery with the costs of close monitoring and the risk of renal deterioration during the period of "watchful waiting".

Our study raises the question of whether it is reasonable to believe that there is this large regional difference in the prevalence of $\mathrm{CH}$ in Europe. If not, is there over-treatment/ control in regions with a high prevalence or is the outcome later in life worse in those regions with low prenatal detection of $\mathrm{CH}$ and therefore an apparently low prevalence of $\mathrm{CH}$ in infancy? The question will be very difficult to answer, but efforts should be done to find the optimal follow-up programme and level of treatment.

\section{Appendix. EUROCAT Working Group}

Joaquín Salvador, Barcelona, Spain, Anna Latos-Bielenska, Poznan, Poland, Isabel Portillo, Basque Country, Spain, Martin Haeusler, Styria, Austria, Marie-Claude Addor, Vaud, Switzerland, Marian K. Bakker, Groningen, The Netherlands, Gioacchino Scarano, Campania, Italy, Awi Wiesel, Mainz, Germany, Johanna Costigan, South-East Ireland, Mary T O'Mahony, Cork, Ireland, David Tucker, Swansea, UK, Catherine de Vigan, Paris, France, Elisa Calzolari, Ferrara, Italy, Berenice Doray, Strasbourg, France, Miriam Gatt, Malta, Gema Ariceta, Basque Country, Spain, Maria Soares, South Portugal, Portugal, Yves Gillerot, Hainaut, Belgium.

\section{References}

[1] Csaicsich D, Greenbaum LA, Aufricht C. Upper urinary tract: when is obstruction obstruction? Curr Opin Urol 2004;14: $213-7$.

[2] Roth JA, Diamond DA. Prenatal hydronephrosis. Curr Opin Pediatr 2001;13:138-41. 
[3] EUROCAT Working Group. Report 8: surveillance of congenital anomalies in Europe 1980-99. University of Ulster; 2002.

[4] Boyd PA, de Vigan C, Khoshnood B, Loane M, Garne E, Dolk H, et al. Survey of screening policies in Europe for structural malformations and chromosome anomalies, and their impact on detection and termination rates for Neural Tube Defects and Down syndrome. Br J Obstet Gynaecol 2008;115:689-96.

[5] Lee RS, Cendren M, Kinnamon DD, Nguyen HT. Antenatal hydronephrosis as a predictor of postnatal outcome: a metaanalysis. Pediatrics 2006;118:586-93.

[6] Ek S, Lidefeldt KJ, Varricio L. Fetal hydronephrosis: prevalence, natural history and postnatal consequences in an unselected population. Acta Obstet Gynecol Scand 2007;86: 1463-6.

[7] Livera L, Brookfield DSK, Egginton JA, Hawnaur JM. Antenatal ultrasonography to detect fetal renal abnormalities: a prospective screening programme. BMJ 1989;298:1421-3.

[8] Rosendahl $H$. Ultrasound screening for fetal urinary tract malformations: a prospective study in general population. Eur J Obstet Gynecol Reprod Biol 1990;36:27-33.

[9] Scott JES, Renwick M. Urological anomalies in the Northern Region Fetal Anomaly Survey. Arch Dis Child 1993;68:22-6.

[10] Cortes D, Jørgensen TM, Rittig S, Thaarup J, Hansen A, Andersen KV, et al. Prenatal diagnosed hydronephrosis and other urological anomalies. Ugeskr Laeger 2006;26:2544-50. 